\title{
REVIEW
}

\section{ER-to-cell surface signalling: calreticulin and cell adhesion}

\author{
Sylvia Papp, Marc P. Fadel and Michal Opas \\ Department of Laboratory Medicine and Pathobiology, University of Toronto, Toronto, Ontario, Canada
}

Received $30^{\text {th }}$ May 2003.

Published online $7^{\text {th }}$ July 2003.

\begin{abstract}
Summary
Cell shape, adhesion, and motility are affected by Ca-regulated pathways, which depend on Ca-binding proteins. One such protein is calreticulin, a ubiquitous and major Ca-binding protein, resident in the ER of eukaryotic cells. In the lumen of the ER, calreticulin is a lectin-like chaperone, sharing this function with an ER-membrane protein, calnexin. Calreticulin also functions as an ER-lumenal $\mathrm{Ca}$ store and plays a central role in intracellular $\mathrm{Ca}$ homeostasis, including the regulation of store-operated $\mathrm{Ca}$ influx via plasma membrane and ER Ca channels. Calreticulin also affects processes outside of the ER; most notably, it modulates expression of several genes, some of them adhesion related, such as vinculin and fibronectin. Curiously, changes in the expression level of calreticulin strongly affect tyrosine phosphorylation of cellular proteins, which is known to affect many adhesion-related functions. Consequently, calreticulin affects cell adhesion via the regulation of expression of proteins important in adhesion, as well as via its effects on intracellular signalling pathways. One of the proteins differentially phosphorylated in a calreticulin-dependent manner is $\beta$-catenin, a structural component of cadherin-mediated adhesion complexes and a part of the Wnt signalling pathway. We suggest that the observed changes in cell adhesiveness may be due to calreticulin's influence on a signalling pathway from the ER, which includes the $\beta$ catenin/vinculin protein system. Differential expression of calreticulin may affect the phosphorylation status of $\beta$-catenin by either inhibition of specific phosphotyrosine kinase(s) or activation of phosphotyrosine phosphatase(s). This is likely to affect the balance between complexed and free $\beta$-catenin and impinge further down on the Wnt signalling. At present, the mechanism by which calreticulin affects gene expression can only be speculated upon, but our data indicate that calreticulin, via its effects on Ca release from the ER, may indirectly control the expression of several genes by interfering with calcineurin activity and the ability of the transcription factor, NFAT-3, to translocate to the nucleus. The activation of calcineurin depends on the sustained release of $\mathrm{Ca}$ from ER stores, which is dependent on calreticulin.

In summary, we propose that calreticulin may be a centrally located connector molecule in a signalling network in the lumen of the ER. Calreticulin is uniquely endowed for such regulation because it is a multifunctional protein that interacts with several other ER proteins in a Ca-dependent manner, suggesting that it may function as a signalling "toggle switch". We therefore hypothesize that calreticulin regulates gene expression by participating in an "ER-tonucleus" signalling pathway, which parallels an "ER-to-cell surface" pathway based upon posttranslational events.
\end{abstract}

Keywords: calreticulin - calcium - adhesion - extracellular matrix 


\section{INTRODUCTION}

The ability of cells to adhere to their underlying substratum is critical for their proliferation, motility, differentiation and ultimately, survival. Adhesion is carefully controlled by the cell and is affected by Ca-regulated pathways. A Ca-binding chaperone of the endoplasmic reticulum (ER), named calreticulin, has been implicated in controlling cell-substratum adhesions. From the lumen of the ER, calreticulin may participate in an ER-to-cell surface signalling pathway, thus regulating the composition/function of adhesion-related molecules at the cell surface and the extracellular matrix (ECM).

\section{CELL-SUBSTRATUM ADHESION}

Cell-substratum adhesions are sites of attachment between the cytoskeleton and ECM proteins. Clustered transmembrane adhesion receptors, namely integrins, are responsible for these attachments, which are crucial in sensing, reacting to and modifying the chemical and physical environment of the cell. There are a few features common to cell substratum adhesions. On the intracellular side, there is a linkage between clustered, ECM ligand occupied adhesion receptors and the cytoskeleton. This linkage can be direct (interaction between adhesion receptor and cytoskeleton) or indirect via adapter or linker molecules. This linkage also creates a site of nucleation and polymerization of cytoskeletal elements for higher order assembly and organization (Fig. 1).

Initial descriptions of cell-substratum interactions were done using a form of microscopy called interference reflection microscopy (IRM), an interferometric technique that directly visualizes the topography of a cell's surface that is adhering to a glass substratum (Curtis 1964, Izzard and Lochner 1976, Verschueren 1985). IRM takes advantage of the interference of wave fronts reflected at the phase boundaries created by the thin layer of culture medium which separates a cell and the glass substratum to which that cell adheres.

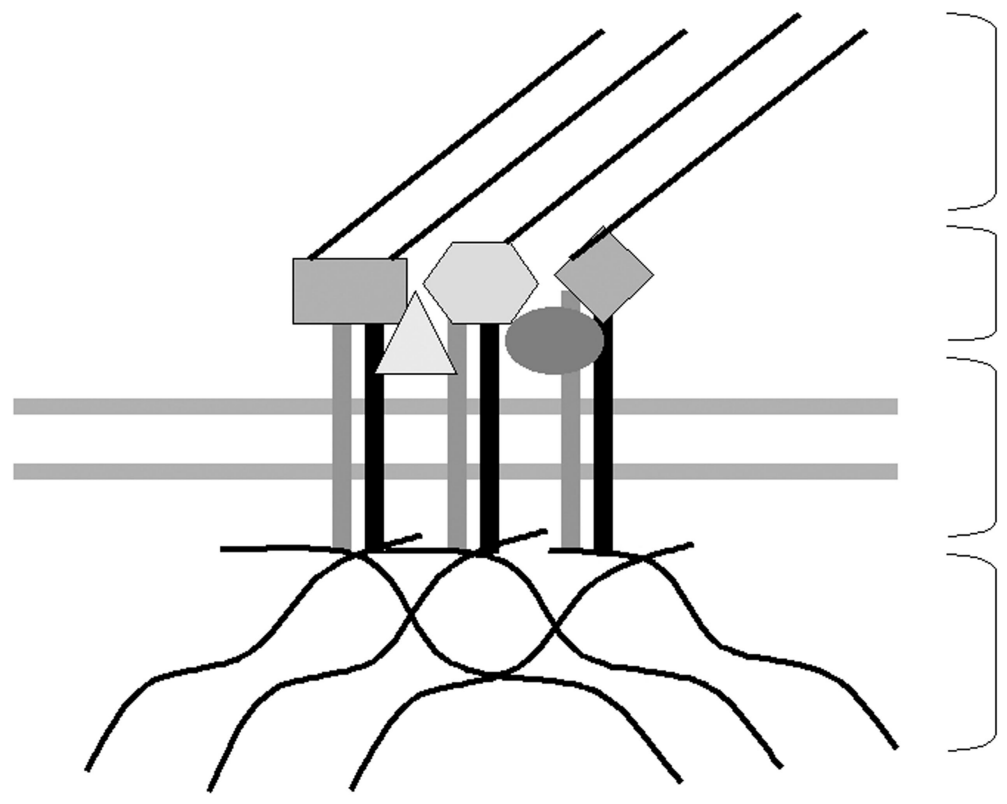

Polymerized cytoskeletal filaments

Cytoplasmic adaptor molecules/ regulatory proteins

Clustered, trans-membrane adhesion receptors

Extracellular matrix fibres

Fig. 1. General structure of cell-substratum adhesions

In monochromatic light, the radiance (i.e., "blackness") of the resultant image can be interpreted in terms of the distance of separation between the cell and the substratum (Izzard and Lochner 1976, Gingell and Todd 1979, BereiterHahn et al. 1979, Gingell 1981). Cells can form many different types of adhesions to the substratum, however, the best known are focal contacts and close contacts (Izzard and Lochner 1976). Both focal and close contacts have been defined in terms of the closeness of the cell's ventral surface to the substratum by IRM. Focal contacts have been extensively characterized, both at the biochemical and microscopic level (for reviews see (Burridge et al. 1997, Geiger and Bershadsky 2001, Geiger et al. 2001). When viewed by IRM (Curtis 1964, Izzard and Lochner 1976), focal contacts appear as discrete ( $c a .10$ by $0.5 \mu \mathrm{m}$ ) black patches and represent the 
areas of closest approach of the ventral cell membrane to the substratum (10-15 $\mathrm{nm}$ or less). Structurally, focal contacts associate with termini of stress fibres (Heath and Dunn 1978) and are the sites of linkage of the actin cytoskeleton to the ECM via integrins (Chen et al. 1985b). Many "focal adhesion proteins" such as focal adhesion kinase (pp125 $5^{\mathrm{FAK}}$ ), paxillin, talin, $\alpha$-actinin and vinculin have been shown to localize there (Jockusch et al. 1995, Burridge and ChrzanowskaWodnicka 1996, Burridge et al. 1997, Geiger et al. 2001, Zamir and Geiger 2001). It is thought that these cytoplasmic proteins have a role in stabilizing the focal contact after its formation and in signal transduction through integrins clustered there (Hynes 1992, Burridge and Chrzanowska-Wodnicka 1996). To exert their function, integrins must be clustered into a focal contact (Yamada and Miyamoto 1995). The clustering depends on several phosphotyrosine (P-Tyr) kinases and phosphatases and is aided by focal contact proteins such as paxillin, talin and vinculin (Angers-Loustau et al. 1999, Sastry and Burridge 2000, Geiger et al. 2001). Focal contacts promote strong cellsubstratum adhesion, however, cell adhesion can be effectively accomplished in other ways. For example, many cancer cells may lack focal contacts, but will still adhere well to the substratum via adhesive structures known as podosomes (Shriver and Rohrschneider 1981) and, more often, close contacts. Relatively little is known about close contacts. The ventral cell membrane is separated from the substratum by a distance of $20-50 \mathrm{~nm}$ in close contacts and they appear as broad grey areas by IRM (Izzard and Lochner 1976). Close contacts are interesting yet elusive structures the have not been extensively studied, despite their importance in cell adhesion and migration. The only biochemical feature attributed to close contacts thus far is the presence of sub-membranous densities parallel to the plasma membrane actin meshwork (Adams 2001). A diffuse localization of $\alpha$-actinin has also been shown for some cells (Chen and Singer 1982). Close contacts are the main form of adhesion to the substratum in cells lacking focal contacts, such as blood borne cells (Kolega et al. 1982, Yürüker and Niggli 1992). Finally, areas of a cell's underside characterized by a cell-substratum separation distance of $100 \mathrm{~nm}$ or more are considered nonadherent and appear white by IRM.

\section{FOCAL CONTACTS IN SIGNALLING}

Focal contacts, besides containing structural proteins such as actin, $\alpha$-actinin, talin, and vinculin (which is a target of tyrosine (Tyr) kinases (Sefton and Hunter 1981), contain many regulatory proteins (Burridge and Chrzanowska-Wodnicka 1996, Sastry and Burridge 2000). These are: pp $125^{\mathrm{FAK}}$ (Guan and Shalloway 1992, Hanks et al. 1992, Otey 1996), paxillin, which is a major substrate for Tyr kinases and interacts with vinculin in vitro (Turner et al. 1990, Burridge et al. 1992); tensin, which has an $\mathrm{SH}_{2}$ domain (Davis et al. 1991) and is phosphorylated in an adhesion-dependent manner; and zyxin, an $\alpha$-actinin-binding protein which has proline-rich motifs that are also present in pp $125^{\mathrm{FAK}}$ (Crawford and Beckerle 1991, Sadler et al. 1992, Crawford et al. 1992). In addition, regulatory proteins such as protein kinase C (PKC) (Jaken et al. 1989, Hyatt et al. 1990), small GTP-ases (Parsons 1996, Rottner et al. 1999, Fukata et al. 1999, Critchley 2000, Schwartz and Shattil 2000, Ridley 2001), src (Liebl and Martin 1992, Li et al. 2002) and most likely others (Maher et al. 1985, Beckerle et al. 1987) are present in focal contacts. Furthermore, the clustering and immobilization of integrins in focal contacts appears to participate in cell signalling (Schwartz et al. 1991, Kornberg et al. 1991, Guan et al. 1991, McNamee et al. 1993) via Tyr kinase activation (Kornberg and Juliano 1992, Juliano and Haskill 1993). Protein phosphorylation on Tyr appears to regulate the function of focal contacts (Rohrschneider et al. 1982, Kellie 1988, Kornberg and Juliano 1992). Attachment of cells to ECM-coated substrata and clustering of integrins causes enhanced Tyr phosphorylation of a 115$130 \mathrm{kDa}$ complex of proteins (Kornberg et al. 1991, Guan et al. 1991, Hanks et al. 1992, Burridge et al. 1992, Kornberg et al. 1992) including that of pp $125^{\text {FAK }}$ Inhibition of $\mathrm{pp} 125^{\text {FAK }} \mathrm{Tyr}$ phosphorylation inhibits formation of focal contacts and stress fibres (Burridge et al. 1992). Focal contact-mediated adhesion is itself regulated by the activation of protein kinases (Kellie 1988, Hunter 1989, Chen 1990, Kellie et al. 1991, Kornberg and Juliano 1992). For example, activation of PKC by growth factors and tumour promoters is accompanied by changes in cell adhesion and affects focal contacts (Martini and Schachner 1986, Meigs and Wang 1986, Herman et al. 1987, Turner et al. 1989, Woods and Couchman 1992, Zhou et al. 1993), and oncogenic viruses which encode Tyr kinases (e.g., $s r c$ ) have dramatic effects on cell shape and cell adhesion (RoAlbeit hrschneider et al. 1982, Kellie 1988, Burridge et al. 1988, Chen 1990, Kellie et al. 1991). Collectively, aside from fulfilling an important structural function, focal contacts comprise important signalling entities, both regulatory and regulated (Sastry and Burridge 2000, Schaller 2001). 


\section{THE ROLE OF CALRETICULIN IN CELL- SUBSTRATUM ADHESIONS}

Cell-substratum adhesions may be regulated by many factors, including soluble factors, cell- and substratum-bound proteins and intracellular products of specific genes. Protein phosphorylation on Tyr appears to regulate the function of many cell adhesions (Kellie 1988, Volberg et al. 1991, Burridge et al. 1992, Kornberg and Juliano 1992, Volberg et al. 1992, Burridge and Chrzanowska-Wodnicka 1996, Hanks and Polte 1997, Daniel and Reynolds 1997). Furthermore, cell adhesion is affected by Ca-regulated pathways that depend on a plethora of Ca-binding proteins. Special emphasis here is on the role of calreticulin, a $\mathrm{Ca}$ binding chaperone ubiquitously expressed in the SR/ER of eukaryotic cells (Michalak et al. 1999, Johnson et al. 2001). From the lumen of the ER/SR, calreticulin acts as a chaperone and affects $\mathrm{Ca}$ homeostasis, gene expression and cell adhesion (Michalak et al. 1999,
Johnson et al. 2001). In the ER, calreticulin has an important role in the quality control process during the synthesis and folding of proteins, including but not limited to ion channels and cell surface receptors. It is thought that calreticulin acts in a $\mathrm{Ca}$ sensitive manner in concert with other ER chaperones, including its transmembrane relative calnexin, to assist in the folding of newly translocated nascent glycoproteins (Helenius et al. 1997). Structural and functional analyses of calreticulin suggest that it has three domains: the highly conserved $\mathrm{N}$-domain, the proline-rich $\mathrm{P}$-domain and the acidic C-domain. The N- and P-domains of calreticulin are responsible for chaperoning activity while the $\mathrm{C}$-domain carries out the Ca storage function (Fliegel et al. 1989a, Fliegel et al. 1989b, Nakamura et al. 2001). The remarkably high degree of conservation of calreticulin across species implies its fundamental importance (Fig. 2).

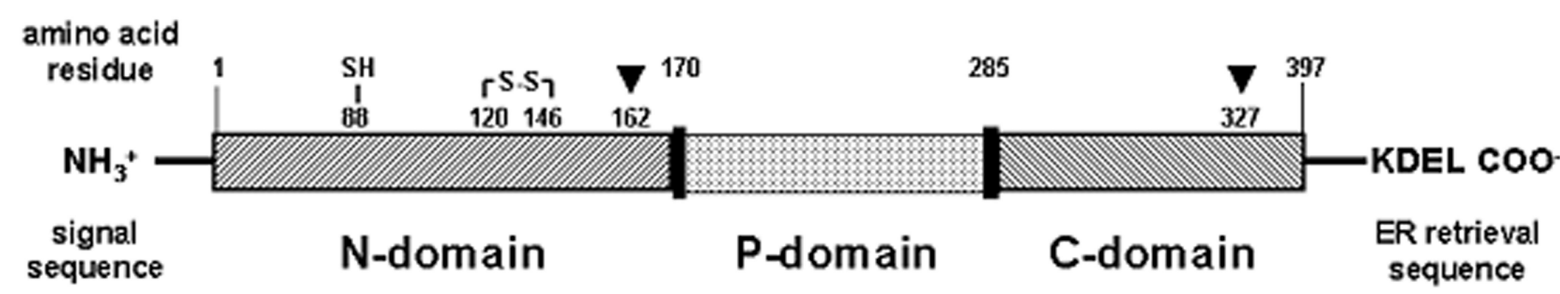

Fig. 2. Structural analysis of calreticulin suggests that it has three domains: The N-domain of calreticulin is the most conserved domain among all calreticulin so far cloned. In vitro, the N-domain interacts with the DNA binding domain of the glucocorticoid receptor. The N-domain of calreticulin binds $\mathrm{Zn}$ and interacts with protein disulfide isomerase (PDI) and ERp57. The next domain of calreticulin has been designated the P-domain. This region of the protein is proline-rich and contains three sequence repeats of 17 amino acids (PxxIxDPDAxKPEDWDE) and three repeats of the sequence GxWxPPxIxNPxYx. The P-domain of calreticulin is involved in high affinity Ca binding. The P-domain is one of the more interesting regions of the protein because of its lectin-like activity and amino acid sequence similarities to calnexin, calmegin and CALNUC, a Golgi Ca-binding protein. The C-domain of calreticulin is very acidic, terminates with the ER retrieval signal sequence KDEL, and interacts in vitro with a set of ER/SR proteins and with blood clotting factors. Residues \#162 and \#327 are potential N-glycosylation sites and calreticulin binding to carbohydrate may be a "signal" to recruit chaperones such as calnexin to assist in protein folding.

We have shown that the level of calreticulin expression may modulate cell adhesion by the regulation of vinculin expression (Fadel et al. 1999). Transformed fibroblasts stably overexpressing calreticulin develop extensive focal contacts and reorganize their actin into stress fibres (Opas et al. 1996). This is due to the upregulation of vinculin (Fadel et al. 1999). Downregulation of calreticulin causes inverse effects(Leung-Hagesteijn et al. 1994, Opas et al. 1996). The changes in cell adhesion are coincident with changes in the levels of protein Tyr phosphorylation in cells differentially expressing calreticulin (Fadel et al. 1999). The abundance of P-Tyr in cells overexpressing calreticulin is dramatically reduced in comparison to control cells. Importantly, protein phosphorylationdephosphorylation on Tyr comprises one of the major mechanisms regulating cell adhesiveness (Burridge and Chrzanowska-Wodnicka 1996, Hanks and Polte 1997, Daniel and Reynolds 1997). While the mechanism(s) are still elusive, these effects of calreticulin overexpression are universal for several cell types overexpressing calreticulin in a transient, stable or inducible manner (Fadel et al. 1999, Fadel et al. 2001). These data suggest that the changes in cell adhesion may be due to the effects of 
calreticulin on a signalling pathway, which includes vinculin and may involve changes in the activity of Tyr kinases and/or phosphatases. A direct implication of this for cell-substratum interactions is that calreticulin effects may target primarily focal contact-mediated adhesion. This notion derives support from our data (Fadel et al. 1999), which show that the calreticulin expression level does not affect cell adhesion in general, but only the vinculin-dependent focal contact formation. Briefly, Fadel et al. (Fadel et al. 1999) has shown that calreticulin underexpressing retinal pigment epithelial cells lack focal contacts, while the cells that express calreticulin abundantly develop numerous and prominent focal contacts. Importantly, after the calreticulin underexpressing retinal pigment epithelial cells were transfected with a calreticulin vector, both the expression of calreticulin and vinculin increased and the cells developed prominent focal contacts. Calreticulin underexpressing retinal pigment epithelial cells that lack focal contacts are not adhesion-deficient and adhere to the substratum with vast areas of close contacts. Curiously, focal contacts can be induced in these cells by a variety of means, thus implying that while components necessary to assemble focal contacts are all present in the calreticulin underexpressing cells, perhaps a stimulus to form them is missing.

\section{DIVERSITY OF CELL-SUBSTRATUM ADHESIONS: THE ROLE OF CALRETICULIN}

Initially, focal contacts were defined in terms of the separation distance between the cell's ventral surface and the substratum by IRM (Curtis 1964, Izzard and Lochner 1976). More recently, the nature of focal contacts has been re-examined. This has led to the re-emergence of a type of adhesion called the fibrillar adhesion. The fibrillar adhesion was originally identified and characterized by I.I. Singer as the fibronexus (Singer 1979, Singer 1982) and then by W.-T. Chen and S.J. Singer as the ECM contact (Chen and Singer 1982, Chen et al. 1985a). Fibrillar adhesions are usually found in the central region of cells and can range in size from $1-10 \mu \mathrm{m}$. Fibrillar adhesions link the cytoskeleton to proteins of the ECM, especially fibronectin fibrils. On the cytoplasmic side, they are enriched in the molecule tensin, and are currently thought to emerge or "mature" out of focal contacts found at the periphery of the cell. Importantly, unlike "classical" focal contacts, fibrillar adhesions tend to generate a weakly grey or no IRM image. Since an IRM image is generated by the interference of wavefronts reflected from glass/medium and medium/cell surface phase boundaries, the intensity of reflection depends on the refractive index differential at the boundary (Bereiter-Hahn et al. 1979). In a "typical" configuration of glass/medium/cell, the radiance IRM image is a function of the distance between the glass and the cell's underside and typically, the areas of closest approach of the ventral cell membrane to the substratum, i.e., "classical" focal contacts, generate black zero order interference. In the case of heavy accumulation of ECM in the contact area, the refractive index of the "medium" will increase causing increase in radiance: consequently IRM images of ECM accumulations do not have to be black (Opas 1988). This is why IRM images of fibrillar adhesions have less contrast than images of focal contacts.

The view of cell-substratum adhesions is becoming increasingly complex and has been the subject of several recent excellent and extensive reviews (Geiger and Bershadsky 2001, Geiger et al. 2001, Zamir and Geiger 2001). Over 50 different molecules have been shown to co-localize to focal contacts either transiently or stably (Geiger et al. 2001). Knock out analysis of major focal contact molecules have emphasized their important role. For example, the vinculin knockout mouse is lethal due to brain and heart defects (Xu et al. 1998). It is interesting to note that the calreticulin knock out mouse has a similar phenotype, also resulting in brain and heart defects (Mesaeli et al. 1999, Rauch et al. 2000).

Focal contacts and fibrillar adhesions have an important role in the deposition and remodelling of the ECM, especially fibronectin. Both focal contacts and fibrillar adhesions have been implicated in fibronectin matrix assembly. Both have been shown to contain clustered $\alpha_{5} \beta_{1}$ integrins (fibronectin receptor), and both are connected to the actin cytoskeleton. A more recent view is that focal contacts preferentially contain $\alpha_{\mathrm{v}}$ integrins, while fibrillar adhesions are enriched in $\alpha_{5}$ integrins. Focal contacts are the sites of exertion of isometric tension by a cell onto the substratum. Fibrillar adhesions arise out of focal contacts in an actin dependent manner towards the cell centre. Stemming from the observation that the fibronectin molecule needs to be stretched by the cell for efficient fibrillogenesis to occur, it is thought that focal contacts and fibrillar adhesions do this in unison. The focal contacts are known to contain clustered, activated integrins and fibronectin matrix assembly sites. The fibronectin molecule could be initially bound by the cell at the focal contact, after which the maturing fibrillar adhesions would pull a portion of the fibronectin molecule with it towards 
the centre of the cell, effectively stretching it and initiating fibrillogenesis (Ohashi et al. 2002).

We have identified the fibronectin gene as being upregulated upon overexpression of calreticulin [Fadel et al submitted]. We assessed the levels of fibronectin gene transcription and protein synthesis with respect to calreticulin expression level. Either inducible overexpression of calreticulin in HEK293 cells or stable overexpression of calreticulin in $\mathrm{L}$ fibroblasts was accompanied by increased levels of fibronectin mRNA and protein. In calreticulin overexpressing L fibroblasts, which are highly adhesive, fibronectin mRNA, protein secretion and matrix deposition were all specifically increased. This was accompanied by increased surface stabilization of $\alpha_{5}$ integrins at focal contacts. Furthermore, attachment to pre-adsorbed fibronectin carpets induced calreticulin overexpressing cells, which were already well spread on glass, to spread more extensively. Calreticulin overexpressers attached to the carpet via predominantly vinculinpositive classical focal contacts, and they also effectively remodelled fibronectin carpets via tensin-positive fibrillar adhesions. Calreticulin underexpressing cells, while poorly spread on glass, were induced to spread very well on fibronectin carpets, where they made nearly exclusively tensinpositive fibrillar adhesions. These contacts are associated with fibronectin fibrils, suggesting that they are fibrillar adhesions. Thus, calreticulin underexpressers, when induced to spread, may compensate for the paucity of vinculin by forming tensin-rich contacts. Induction of classical focal contacts and fibrillar adhesions could further facilitate increase of fibronectin deposition and matrix remodelling in $\mathrm{L}$ fibroblasts plated on fibronectin, as both types of contacts may have a role in fibronectin fibrillogenesis (Pankov et al. 2000, Zamir et al. 2000, Geiger et al. 2001). Thus, calreticulin specifically modulates fibronectin gene activity, protein secretion and matrix assembly, and affects how cells respond to a patterned fibronectin extracellular matrix by modulating focal contact/fibrillar adhesion formation and/or stability.

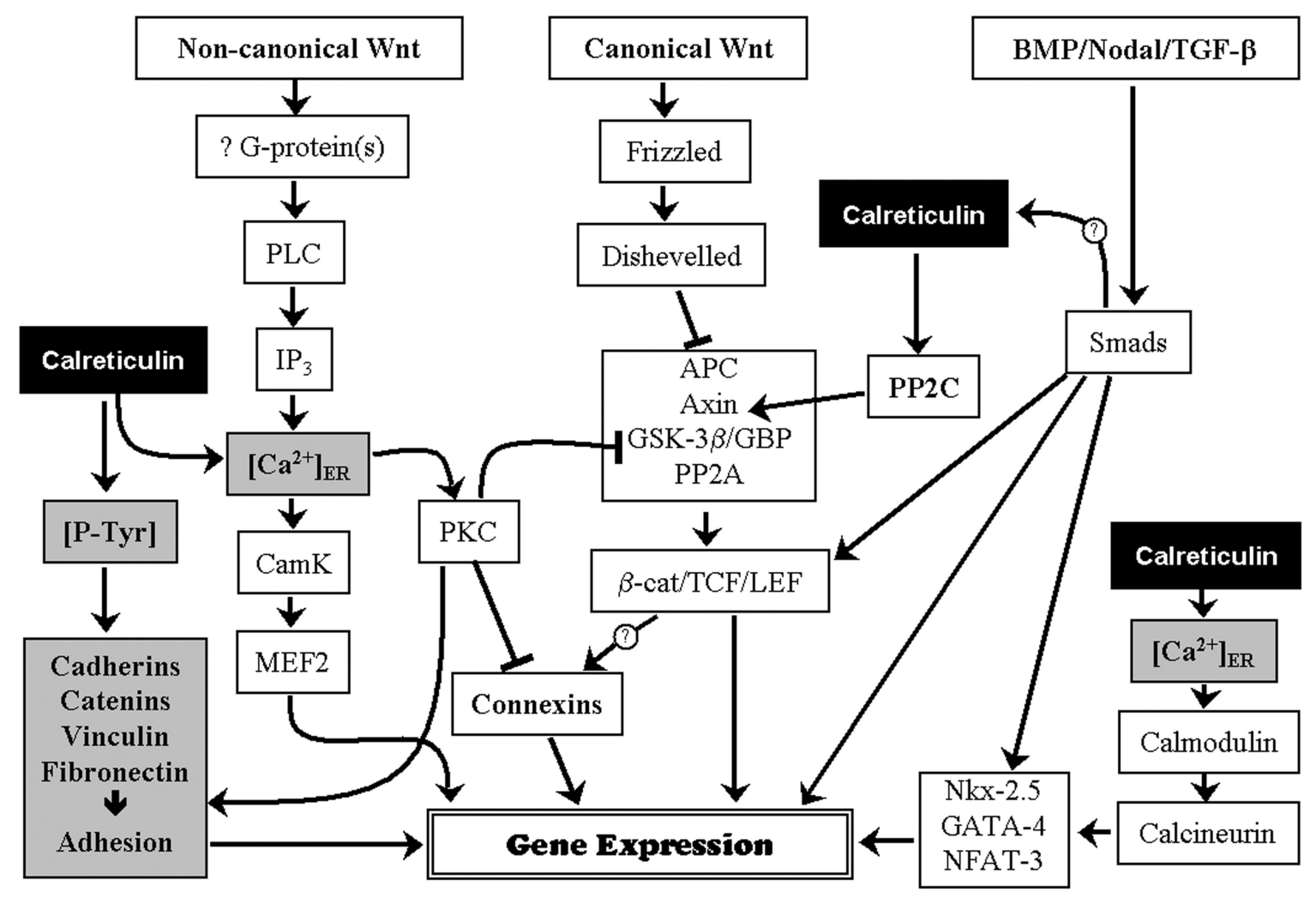

Fig. 3. Hypothetical involvement of calreticulin in major signalling pathways. Shaded boxes denote experimentally proven effects of CRT. 


\section{THE MECHANISM(S) BEHIND CALRETICULIN'S EFFECTS ON CELL ADHESION}

Abundant experimental evidence shows that intracellular calreticulin affects focal contactmediated adhesion (Leung-Hagesteijn et al. 1994, Coppolino et al. 1995, Opas et al. 1996, Coppolino et al. 1997, Fadel et al. 1999, Fadel et al. 2001). Resting cytosolic [Ca] remains the same irrespective of the level of calreticulin in stable calreticulin transfectants, Tet-on inducible cells or calreticulinnull cells (Bastianutto et al. 1995, Mery et al. 1996, Opas et al. 1996, Coppolino et al. 1997, Wang et al. 1997). Thus, cytosolic Ca does not appear to directly mediate the adhesion effects of calreticulin. Calreticulin's chaperone function, while possibly irrelevant to the regulation of vinculin expression, may affect the function of several cell surface receptors, a known example being the bradykinin receptor (Nakamura et al. 2001). Importantly, in calreticulin-depleted cells, the chaperone function of calreticulin is not effectively fulfilled by the calreticulin homologue, calnexin (Knee et al. 2003).

Two alternate explanations have been offered for the calreticulin-mediated effects on cell-substratum adhesions: we have postulated that, by affecting expression of the focal contact-specific protein, vinculin, and the abundance of P-Tyr, calreticulin indirectly regulates cell adhesiveness (Opas et al. 1996, Fadel et al. 1999, Fadel et al. 2001). Another postulate requires that calreticulin regulates cell adhesion directly, by binding the GFFKR sequence of $\alpha$ integrins at the cytoplasmic face of the cell surface (Dedhar 1994, Coppolino et al. 1995). This postulate is based on the observations that, in vitro, calreticulin binds the synthetic peptide KxGFFKR (Rojiani et al. 1991, Burns et al. 1994b), the sequence of which is derived from the conserved sequence of $\alpha$-integrin subunits (Williams et al. 1994), as well as from the DNA binding motifs of receptors for thyroid hormone, steroid hormone, retinoic acid and orphan receptor ligands (Laudet et al. 1991). Recently, it was reported that calreticulinintegrin interaction occurs transiently and is maximal at 10-30 min. after cell plating (Coppolino and Dedhar 1999). To regulate integrin activity in vivo by direct binding, there must be focal contactassociated (cytoplasmic) calreticulin. However, to date, neither we (Michalak et al. 1996, Opas et al. 1996) nor others (Bastianutto et al. 1995) could detect any cytoplasmic or focal contact-associated calreticulin. When we overexpress a full length Green Fluorescent Protein (GFP) coupled to calreticulin (GFP::CRT) and follow it in living cells, it is not found outside of the ER (Opas et al. 1996) and when we overexpress cytoplasmically- targeted GFP::CRT and follow it in the cytoplasm of living cells, it is not found in focal contacts [unpublished data]. Furthermore, targeting of calreticulin to the cytoplasm either by microinjection [unpublished data] or by expression of a leaderless calreticulin has no effect on cell morphology, the cytoskeleton or cell adhesion. Hence, we conclude that cytoplasmic calreticulin, if it exists, is neither detectable nor functional in terms of regulating cell adhesion. It must be stated, however, that a recent paper shows biochemical evidence for cytosolic calreticulin (Holaska et al. 2001). Most importantly, however, we have published evidence that both transcriptional activation by steroid receptors and cell adhesion in vivo are affected only by the full length, ERtargeted form of calreticulin but not by a truncated, cytosolically-targeted mutant protein (Michalak et al. 1996, Opas et al. 1996, Fadel et al. 1999).

At the present time, the mechanisms by which calreticulin modulates gene expression can only be speculated upon. While cytosolic $\mathrm{Ca}$ does mediate the adhesion effects of calreticulin, a putative role of calreticulin in signalling within the ER may impinge on a variety of Ca-sensitive functions including the modulation of gene expression. Transcriptional activation of the glucocorticoid and androgen receptors in vivo is inhibited in cells overexpressing full length calreticulin (Dedhar et al. 1994, Desai et al. 1996, Michalak et al. 1996, Shago et al. 1997). In vivo, full length ER-resident calreticulin inhibits transcriptional activation by the vitamin D3 receptor (Wheeler et al. 1995, StArnaud et al. 1995). Overexpression of calreticulin affects vitamin D3-dependent differentiation of osteoblasts and matrix mineralization (St-Arnaud et al. 1995), retinoic acid-induced gene expression (Desai et al. 1996, Shago et al. 1997) and retinoic acid-dependent differentiation of P19 cells (Dedhar et al. 1994). Finally, we have shown that calreticulin affects fibronectin gene expression. The direct link between calreticulin and fibronectin gene expression is unknown, and the regulation of the fibronectin gene is complex (Senger et al. 1983, Schwarzbauer 1991, Kornblihtt et al. 1996). Fibronectin gene expression is sensitive to cAMP, glucocorticoid and vitamin D signalling pathways (Dean 1989, Schwarzbauer 1991, Kornblihtt et al. 1996), all of which may be affected by calreticulin expression level (Michalak et al. 1999).

An interesting and not well-understood effect of calreticulin is that on the Tyr phosphorylation of cellular proteins. The reduced Tyr phosphorylation observed in cells overexpressing calreticulin can be also achieved by the induction of ER stress (Fadel et al. 1999). However, calreticulin's effects on Tyr phosphorylation are unlikely to be a part of a 
simple stress response, since the two-fold overexpression of calreticulin is not sufficient to cause ER overload and is not accompanied by other changes considered to be typical of a stressed ER (McMillan et al. 1994, Pahl and Baeuerle 1997b, Chapman et al. 1998, Kaufman 1999). The transcription factor NF- $\kappa$ B, which is activated by $\mathrm{Ca}$ release from a stressed ER (Pahl and Baeuerle 1997a), is not affected by changes in calreticulin expression [unpublished]. These observations suggest that calreticulin-dependent modulation of cell adhesiveness involves pathways related to, but different from the ER signalling pathways that have already been described (McMillan et al. 1994, Pahl and Baeuerle 1997b, Chapman et al. 1998, Kaufman 1999).

One of the proteins undergoing Tyr dephosphorylation in calreticulin-overexpressing cells is $\beta$-catenin, a structural component of cadherin-mediated adhesion complexes, a member of the armadillo protein family, thus linking calreticulin to the canonical Wnt signalling pathway (Seidensticker and Behrens 2000, Fadel et al. 2001). Tyr dephosphorylated $\beta$-catenin is stabilized in junctional complexes (Hazan et al. 1997, Hazan and Norton 1998). When phosphorylated, $\beta$-catenin on Tyr displaces to the cytoplasm, where it may participate in Wnt signalling (Barth et al. 1997, Eastman and Grosschedl 1999, Behrens 1999). From the cytoplasm, Tyr phosphorylated $\beta$-catenin may translocate to the nucleus where it acts as a transcription factor (Ben-Ze'ev 1997, Barth et al. 1997, Huttenlocher et al. 1998, Piedra et al. 2001). Phosphorylation of $\beta$-catenin by a serine/threonine (Ser/Thr) kinase, glycogen synthase kinase- $3 \beta$, targets $\beta$-catenin for degradation (Seidensticker and Behrens 2000). The overexpression of calreticulin may affect the phosphorylation status of $\beta$-catenin, either by the inhibition of specific P-Tyr kinase(s) or activation of $\mathrm{P}$-Tyr phosphatase(s). In addition to signalling via stabilizing cytosolic $\beta$-catenin by some Wnts, i.e., via canonical pathway, other Wnts signal by stimulation of the release of $\mathrm{Ca}$ from the ER and the activation of PKC and Ca-calmodulindependent protein kinase II, i.e., via non-canonical pathway (Miller et al. 1999, Kuhl et al. 2000). PKC appears to participate in both Wnt/ $\beta$-catenin and Wnt/Ca pathways (Wakasaki et al. 1997, Chen et al. 2000). Both modes of Wnt signalling may impinge on several facets of development, including gap junctional communication (van der Heyden et al. 1998, Ai et al. 2000) and cell adhesion (Miller et al. 1999, Peifer and Polakis 2000, Kalcheim 2000, Christiansen et al. 2000, Hecht and Kemler 2000).

So far, the best studied effect of calreticulin on gene expression concerns the transcription factor NFAT-3. To translocate to the nucleus, NFAT-3 has to be dephosphorylated by calcineurin, a Ca- and calmodulin-dependent protein phosphatase (Shibasaki et al. 1996, Rao et al. 1997). The activation of calcineurin depends on the sustained release of $\mathrm{Ca}$ from ER stores (Dolmetsch et al. 1997, Dolmetsch et al. 1998, Li et al. 1998), which is dependent on calreticulin abundance (Bastianutto et al. 1995, Mery et al. 1996, Fasolato et al. 1998). Thus, calreticulin may indirectly regulate calcineurin activity by affecting Ca release from the ER/SR and the ability of NFAT-3 to translocate to the nucleus. Indeed, we have shown that nuclear import of NFAT-3 transcription factor is impaired in calreticulin-null cells and transfection of calreticulin-null cells with calreticulin expression vector restores NFAT-3 nuclear translocation (Mesaeli et al. 1999).

\section{CONCLUDING REMARKS}

Recent data suggest that calreticulin may be a centrally located connector molecule in a signalling network in the lumen of the ER (Fig. 3; Michalak et al. 1999). Calreticulin is uniquely endowed for such regulation because its $\mathrm{Ca}$ binding may (I) regulate the free [Ca] within the ER lumen (Bastianutto et al. 1995, Mery et al. 1996, Fasolato et al. 1998), (II) regulate the function of $\mathrm{Ca}$ transport molecules such as SERCA2b and/or the $\mathrm{IP}_{3}$ receptor (Camacho and Lechleiter 1995, Jouaville et al. 1995, John et al. 1998), (III) affect the function of the store operated $\mathrm{Ca}$ channels (Bastianutto et al. 1995, Mery et al. 1996, Fasolato et al. 1998), and finally, (IV) affect transcriptional activity of several genes (Burns et al. 1994a). Calreticulin interacts with several other ER proteins in a Ca-dependent manner (Baksh et al. 1995, Zapun et al. 1998), suggesting that it may function as a signalling "toggle switch". We therefore hypothesize that ER-resident calreticulin regulates gene expression by participating in an ER-tonucleus signalling pathway (Michalak et al. 1999, Johnson et al. 2001). Our focus has been on the expression of vinculin and fibronectin, two key players in cell-substratum adhesions. In addition, evidence points to the existence of distinct ER-tocell surface signalling pathways also involving calreticulin. Cell-substratum adhesions are complex both at the molecular and functional level. The integrity and function of such adhesions depends on a variety of factors ranging from the phosphorylation state of their component molecules, to the tension they are able to generate, and to the levels of $\mathrm{Ca}$ available. Calreticulin may affect any of these conditions, thus we postulate that it is a 
key player in the regulation of cell-substratum adhesions.

\section{ACKNOWLEDGEMENTS}

S.P. is a recipient of a Doctoral Research Award from the Canadian Institutes for Health Research. M.P.F. was a recipient of a joint Doctoral Research Award from the Canadian Institutes for Health Research and the Heart and Stroke Foundation of Canada. M.O. is a member of Heart \& Stroke/Richard Lewar Centre of Excellence. This work was supported by grants from the Canadian Institutes for Health Research and the Heart and Stroke Foundation of Ontario.

Simultaneously published in J. Berger (ed): Advance in Cell Biology. Kopp Publ., České Budějovice 2003, pp. 79-112.

\section{REFERENCES}

Adams J.C.: Cell-matrix contact structures. Cell.Mol.Life Sci. 58:371-392, 2001.

Ai Z., A. Fischer, D.C. Spray, A.M. Brown, G.I. Fishman: Wnt-1 regulation of connexin43 in cardiac myocytes. J. Clin. Invest 105: 161$171,2000$.

Angers-Loustau A., J.F. Côté, M.L. Tremblay: Roles of protein tyrosine phosphatases in cell migration and adhesion. Biochem. Cell Biol. 77:493-505, 1999.

Baksh S., K. Burns, C. Andrin, M. Michalak: Interaction of calreticulin with protein disulfide isomerase. J. Biol. Chem. 270: 31338-31344, 1995.

Barth A.I., I.S. Näthke, W.J. Nelson: Cadherins, catenins and APC protein: interplay between cytoskeletal complexes and signaling pathways. Curr. Opin. Cell Biol. 9:683-690, 1997.

Bastianutto C., E. Clementi, F. Codazzi, P. Podini, F. De Giorgi, R. Rizzuto, J. Meldolesi, T. Pozzan: Overexpression of calreticulin increases the $\mathrm{Ca}^{2+}$ capacity of rapidly exchanging $\mathrm{Ca}^{2+}$ stores and reveals aspects of their lumenal microenvironment and function. J. Cell Biol. 130: 847-855, 1995.

Beckerle M.C., K. Burridge, G.N. DeMartino, D.E. Croall: Colocalization of calciumdependent protease II and one of its substrates at sites of cell adhesion. Cell 51: 569-577, 1987.
Behrens J.: Cadherins and catenins: Role in signal transduction and tumor progression. Cancer Metastasis Rev. 18: 15-30, 1999.

Ben-Ze'ev A.: Cytoskeletal and adhesion proteins as tumor suppressors. Curr. Opin. Cell Biol. 9: 99-108, 1997.

Bereiter-Hahn J., C.H. Fox, B. Thorell: Quantitative reflection contrast microscopy of living cells. J. Cell Biol. 82: 767-779, 1979.

Burns K., E.A. Atkinson, R.C. Bleackley, M. Michalak: Calreticulin: From $\mathrm{Ca}^{2+}$ binding to control of gene expression. Trends Cell Biol. 4: 152-154, 1994a.

Burns K., B. Duggan, E.A. Atkinson, K.S. Famulski, M. Nemer, R.C. Bleackley, M. Michalak. Modulation of gene expression by calreticulin binding to the glucocorticoid receptor. Nature 367:476-480, 1994b.

Burridge K. and M. Chrzanowska-Wodnicka: Focal adhesions, contractility, and signaling. Annu. Rev. Cell Dev. Biol. 12: 463-518, 1996.

Burridge K., M. Chrzanowska-Wodnicka, C.L. Zhong: Focal adhesion assembly. Trends Cell Biol. 7: 342-347, 1997.

Burridge K., K. Fath, T. Kelly, G. Nuckolls, C. Turner: Focal adhesions: transmembrane junctions between the extracellular matrix and the cytoskeleton. Annu. Rev. Cell Biol. 4: 487525, 1988.

Burridge K., C.E. Turner, L.H. Romer: Tyrosine phosphorylation of paxillin and $\mathrm{pp} 125^{\mathrm{FAK}}$ accompanies cell adhesion to extracellular matrix: A role in cytoskeletal assembly. J. Cell Biol. 119: 893-903, 1992.

Camacho P. and J.D. Lechleiter: Calreticulin inhibits repetitive intracellular $\mathrm{Ca}^{2+}$ waves. Cell 82:765-771, 1995.

Chapman R., C. Sidrauski, P. Walter: Intracellular signaling from the endoplasmic reticulum to the nucleus. Annu. Rev. Cell Dev. Biol. 14: 459485, 1998.

Chen R.H., W.V. Ding, F. McCormick: Wnt signaling to $\beta$-catenin involves two interactive components - Glycogen synthase kinase- $3 \beta$ inhibition and activation of protein kinase $\mathrm{C}$. J. Biol. Chem. 275: 17894-17899, 2000.

Chen W.-T.: Transmembrane interactions at cell adhesion and invasion sites. Cell Differ. Dev. 32: 329-336, 1990.

Chen W.-T., J.M. Greve, D.I. Gottlieb, S.J. Singer: Immunocytochemical localization of $140 \mathrm{kD}$ cell adhesion molecules in cultured chicken fibroblasts, and in chicken smooth muscle and intestinal epithelial tissues. J. Histochem. Cytochem. 33: 576-586, 1985a.

Chen W.-T., E. Hasegawa, T. Hasegawa, C. Weinstock, K.M. Yamada: Development of 
cell surface linkage complexes in cultured fibroblasts. J.Cell Biol. 100: 1103-1114, 1985b.

Chen,W.-T. and S.J. Singer: Immunoelectron microscopic studies of the sites of cell-substratum and cell-cell contacts in cultured fibroblasts. J.Cell Biol. 95: 205-222, 1982.

Christiansen J.H., E.G. Goles, D.G. Wilkinson: Molecular control of neural crest formation, migration and differentiation. Curr. Opin. Cell Biol. 12: 719-724, 2000.

Coppolino M., C. Leung-Hagesteijn, S. Dedhar, J. Wilkins: Inducible interaction of integrin $\alpha_{2} \beta_{1}$ with calreticulin - Dependence on the activation state of the integrin. J. Biol. Chem. 270: 23132-23138, 1995.

Coppolino M.G. and S. Dedhar: Ligand-specific, transient interaction between integrins and calreticulin during cell adhesion to extracellular matrix proteins is dependent upon phosphorylation dephosphorylation events. Biochem. J. 340 :41-50, 1999.

Coppolino M.G., M.J. Woodside, N. Demaurex, S. Grinstein, R. St-Arnaud, S. Dedhar: Calreticulin is essential for integrin-mediated calcium signalling and cell adhesion. Nature 386: 843-847, 1997.

Crawford A.W. and M.C. Beckerle: Purification and characterization of zyxin, an 82,000-dalton component of adherens junctions. J. Biol. Chem. 266: 5847-5853, 1991.

Crawford A.W., J.W. Michelsen, M.C. Beckerle: An interaction between zyxin and $\alpha$-actinin. J.Cell Biol. 116:1381-1393, 1992.

Critchley D.R.: Focal adhesions - the cytoskeletal connection. Curr. Opin. Cell Biol. 12: 133-139, 2000.

Curtis A.S.G.: The mechanism of adhesion of cells to glass. J. Cell Biol. 20: 199-215, 1964.

Daniel J.M. and A.B. Reynolds: Tyrosine phosphorylation and cadherin/catenin function. BioEssays 19:883-891, 1997.

Davis S., M.L. Lu, S.H. Lo, S. Lin, J.A. Butler, B.J. Druker, T.M. Roberts, Q. An, L.B. Chen: Presence of an SH2 domain in the actin-binding protein tensin. Science 252:712-715, 1991.

Dean D.C.: Expression of the fibronectin gene. Am. J. Respir. Cell Mol. Biol. 1: 5-10, 1989.

Dedhar S.: Novel functions for calreticulin: Interaction with integrins and modulation of gene expression. Trends Biochem.Sci. 19:269271, 1994.

Dedhar S., P.S. Rennie, M. Shago, C.-Y. LeungHagesteijn, H. Yang, J. Filmus, R.G. Hawley, N. Bruchovsky, H. Cheng, R.J. Matusik, V. Giguère: Inhibition of nuclear hormone receptor activity by calreticulin. Nature 367:480-483, 1994.
Desai D., M. Michalak, N.K. Singh,.R.M. Niles: Inhibition of retinoic acid receptor function and retinoic acid- regulated gene expression in mouse melanoma cells by calreticulin - A potential pathway for cyclic AMP regulation of retinoid action. J. Biol. Chem. 271: 1515315159, 1996.

Dolmetsch R.E., R.S. Lewis, C.C. Goodnow, J.I. Healy: Differential activation of transcription factors induced by $\mathrm{Ca} 2+$ response amplitude and duration. Nature 386:855-858, 1997.

Dolmetsch R.E., K.L. Xu, R.S. Lewis: Calcium oscillations increase the efficiency and specificity of gene expression. Nature 392:933-936, 1998.

Eastman Q. and R. Grosschedl: Regulation of LEF$1 / \mathrm{TCF}$ transcription factors by Wnt and other signals. Curr. Opin. Cell Biol. 11: 233-240, 1999.

Fadel M.P., E. Dziak, C.M. Lo, J. Ferrier, N. Mesaeli, M. Michalak, M. Opas: Calreticulin affects focal contact-dependent but not close contact-dependent cell-substratum adhesion. J.Biol.Chem. 274: 15085-15094, 1999.

Fadel M.P., M. Szewczenko-Pawlikowski, P. Leclerc, E. Dziak, J.M. Symonds, O. Blaschuk, M. Michalak, M. Opas: Calreticulin affects beta-catenin associated pathways. J.Biol.Chem. 276:27083-27089, 2001.

Fasolato,C., P. Pizzo, T. Pozzan: Delayed activation of the store-operated calcium current induced by calreticulin overexpression in RBL-1 cells. Mol.Biol.Cell 9: 1513-1522, 1998.

Fliegel L., K.Burns, D.H. MacLennan, R.A.F. Reithmeier, M. Michalak: Molecular cloning of the high affinity calcium-binding protein (calreticulin) of skeletal muscle sarcoplasmic reticulum. J. Biol. Chem. 264: 21522-21528, 1989a.

Fliegel L., K. Burns, M. Opas, M. Michalak: The high-affinity calcium binding protein of sarcoplasmic reticulum. Tissue distribution, and homology with calregulin. Biochim. Biophys. Acta 982:1-8, 1989b.

Fukata M., M. Nakagawa, S. Kuroda, K. Kaibuchi: Cell adhesion and Rho small GTPases. J.Cell Sci. 112: 4491-4500, 1999.

Geiger B. and A. Bershadsky: Assembly and mechanosensory function of focal contacts. Curr. Opin. Cell Biol. 13: 584-592, 2001.

Geiger B., A. Bershadsky, R. Pankov, K.M. Yamada: Transmembrane crosstalk between the extracellular matrix-cytoskeleton crosstalk. Nat. Rev. Mol. Cell Biol. 2: 793-805, 2001.

Gingell D.: The interpretation of interferencereflection images of spread cells: Significant 
contributions from thin peripheral cytoplasm. J. Cell Sci. 49: 237-247, 1981.

Gingell D. and I. Todd: Interference reflection microscopy. A quantitative theory for image interpretation and its application to cellsubstratum separation measurement. Biophys.J. 26: 507-526, 1979.

Guan J.-L. and D. Shalloway: Regulation of focal adhesion-associated protein tyrosine kinase by both cellular adhesion and oncogenic transformation. Nature 358: 690-692, 1992.

Guan J.-L., J.E. Trevithick, R.O. Hynes: Fibronectin/integrin interaction induces tyrosine phosphorylation of a $120-\mathrm{kDa}$ protein. Cell Regul. 2: 951-964, 1991.

Hanks S.K., M.B. Calalb, M.C. Harper, S.K. Patel: Focal adhesion protein-tyrosine kinase phosphorylated in response to cell attachment to fibronectin. Proc.Natl.Acad.Sci.USA 89: 84878491, 1992.

Hanks S.K. and T.R. Polte: Signaling through focal adhesion kinase. BioEssays 19: 137-145, 1997.

Hazan R.B., L. Kang, S. Roe, P.I. Borgen, D.L. Rimm: Vinculin is associated with the E-cadherin adhesion complex. J.Biol.Chem. 272: 32448-32453, 1997.

Hazan R.B. and L. Norton: The epidermal growth factor receptor modulates the interaction of E-cadherin with the actin cytoskeleton. J.Biol.Chem. 273: 9078-9084, 1998.

Heath J.P. and G.A. Dunn: Cell to substratum contacts of chick fibroblasts and their relation to the microfilament system. A correlated interference- reflexion and high-voltage electronmicroscope study. J.Cell Sci. 29: 197-212, 1978.

Hecht A. and R. Kemler: Curbing the nuclear activities of beta-catenin. Control over Wnt target gene expression. EMBO Rep. 1: 24-28, 2000.

Helenius A., E.S. Trombetta, D.N. Hebert, J.F. Simons: Calnexin, calreticulin and the folding of glycoproteins. Trends Cell Biol. 7: 193-200, 1997.

Herman B., M.W. Roe, C. Harris, B. Wray, D. Clemmons: Platelet-derived growth factorinduced alterations in vinculin distribution in porcine vascular smooth muscle cells. Cell Motil. Cytoskeleton 8: 91-105, 1987.

Holaska J.M., B.E. Black, D.C. Love, J.A. Hanover, J. Leszyk, B.M. Paschal: Calreticulin is a receptor for nuclear export. J. Cell Biol. 152: 127-140, 2001.

Hunter T.: Protein modification: phosphorylation on tyrosine residues. Curr.Opin.Cell Biol. 1: 11681181, 1989.

Huttenlocher A., M. Lakonishok, M. Kinder, S. Wu, T. Truong, K.A. Knudsen, A.F. Horwitz:
Integrin and cadherin synergy regulates contact inhibition of migration and motile activity. J. Cell Biol. 141: 515-526, 1998.

Hyatt S.L., T. Klauck, S. Jaken: Protein kinase C is localized in focal contacts of normal but not transformed fibroblasts. Mol.Carcinog. 3: 4553, 1990.

Hynes R.O.: Integrins: Versatility, modulation, and signaling in cell adhesion. Cell 69: 11-25, 1992.

Izzard C.S. and L.R. Lochner: Cell-to-substrate contacts in living fibroblasts: an interference reflexion study with an evaluation of the technique. J.Cell Sci. 21: 129-159, 1976.

Jaken S., K. Leach, T. Klauck: Association of type 3 protein kinase $\mathrm{C}$ with focal contacts in rat embryo fibroblasts. J. Cell Biol. 109: 697-704, 1989.

Jockusch B.M., P. Bubeck, K. Giehl, M. Kroemker, J. Moscher, M. Rothkegel, M. Rüdiger, K. Schlüter, G. Stanke, J. Winkler: The molecular architecture of focal adhesions. Annu. Rev. Cell Dev. Biol. 11: 379-416, 1995.

John L.M., J.D. Lechleiter, P. Camacho: Differential modulation of SERCA2 isoforms by calreticulin. J.Cell Biol. 142: 963-973, 1998.

Johnson S., M. Michalak, M. Opas, P. Eggleton: The ins and outs of calreticulin: from the ER lumen to the extracellular space. Trends Cell Biol. 11: 122-129, 2001.

Jouaville L.S., F. Ichas, E.L. Holmuhamedov, P. Camacho, J.D. Lechleiter: Synchronization of calcium waves by mitochondrial substrates in Xenopus laevis oocytes. Nature 377: 438-441, 1995.

Juliano R.L. and S. Haskill: Signal transduction from the extracellular matrix. J.Cell Biol. 120: 577-585, 1993.

Kalcheim C.: Mechanisms of early neural crest development: From cell specification to migration. Int. Rev. Cytol. 200: 143-196, 2000.

Kaufman R.J.: Stress signaling from the lumen of the endoplasmic reticulum: coordination of gene transcriptional and translational controls. Genes Dev. 13: 1211-1233, 1999.

Kellie S.: Cellular transformation, tyrosine kinase oncogenes, and the cellular adhesion plaque. BioEssays 8: 25-30, 1988.

Kellie S., A.R. Horvath, M.A. Elmore: Cytoskeletal targets for oncogenic tyrosine kinases. J. Cell Sci. 99: 207-211, 1991.

Knee R., I. Ahsan, N. Mesaeli, R.J. Kaufman, M. Michalak: Compromised calnexin function in calreticulin-deficient cells. Biochem. Biophys. Res. Commun. 304: 661-666, 2003.

Kolega J., M.S. Shure, W.-T. Chen, N.D. Young: Rapid cellular translocation is related to close contacts formed between various cultured cells 
and their substrata. J. Cell Sci. 54: 23-34, 1982.

Kornberg L., H.S. Earp, J.T. Parsons, M. Schaller, R.L. Juliano: Cell adhesion or integrin clustering increases phosphorylation of a focal adhesionassociated tyrosine kinase. J. Biol. Chem. 267: 23439-23442, 1992.

Kornberg L. and R.L. Juliano: Signal transduction from the extracellular matrix: The integrintyrosine kinase connection. Trends Pharmacol. Sci. 13: 93-95, 1992.

Kornberg L.J., H.S. Earp, C.E. Turner, C. Prockop, R.L. Juliano: Signal transduction by integrins: Increased protein tyrosine phosphorylation caused by clustering of $\beta_{1}$ integrins. Proc. Natl. Acad. Sci. USA 88: 8392-8396, 1991.

Kornblihtt A.R., C.G. Pesce, C.R. Alonso, P. Cramer, A. Srebrow, S. Werbajh, A.F. Muro: The fibronectin gene as a model for splicing and transcription studies. FASEB J. 10: 248-257, 1996.

Kuhl M., L.C. Sheldahl, M. Park, J.R. Miller, R.T. Moon: The Wnt/Ca ${ }^{2+}$ pathway: a new vertebrate Wnt signaling pathway takes shape. Trends Genet. 16: 279-283, 2000.

Laudet V., C. Hänni, J. Coll, F. Catzeflis, D. Stehelin: Evolution of the nuclear receptor gene superfamily. EMBO J. 11: 1003-1013, 1991.

Leung-Hagesteijn C.-Y., K. Milankov, M. Michalak, J. Wilkins, S. Dedhar: Cell attachment to extracellular matrix substrates is inhibited upon downregulation of expression of calreticulin, an intracellular integrin $\alpha$-subunitbinding protein. J. Cell Sci. 107: 589-600, 1994.

Li L., M. Okura, A. Imamoto: Focal adhesions require catalytic activity of SRC family kinases to mediate integrin-matrix adhesion. Mol. Cell. Biol. 22: 1203-1217, 2002.

Li W.H., J. Llopis, M. Whitney, G. Zlokarnik, R. Y. Tsien: Cell-permeant caged $\mathrm{InsP}_{3}$ ester shows that $\mathrm{Ca}^{2+}$ spike frequency can optimize gene expression. Nature 392: 936-941, 1998.

Liebl E.C. and G.S. Martin: Intracellular targeting of pp $60^{\text {src }}$ expression: localization of $\mathrm{v}$-src to adhesion plaques is sufficient to transform chicken embryo fibroblasts. Oncogene 7: 24172428, 1992.

Maher P.A., E.B. Pasquale, J.Y. Wang, S.J. Singer: Phosphotyrosine-containing proteins are concentrated in focal adhesions and intercellular junctions in normal cells. Proc. Natl. Acad. Sci. USA 82: 6576-6580, 1985.

Martini R. and M. Schachner: Immunoelectron microscopic localization of neural cell adhesion molecules (L1, N-CAM, and MAG) and their shared carbohydrate epitope and myelin basic protein in developing sciatic nerve. J. Cell Biol. 103: 2439-2448, 1986.

McMillan A., M.-J.Gething, J. Sambrook: Intercompartmental signaling. Curr. Opinion Biotech. 6: 540-545, 1994.

McNamee H.P., D.E. Ingber, M.A. Schwartz: Adhesion to fibronectin stimulates inositol lipid synthesis and enhances PDGF-induced inositol lipid breakdown. J. Cell Biol. 121: 673-678, 1993.

Meigs J.B. and Y.-L. Wang: Reorganization of alpha-actinin and vinculin induced by a phorbol ester in living cells. J. Cell Biol. 102: 14301438, 1986.

Mery L., N. Mesaeli, M. Michalak, M. Opas, D.P. Lew, K.-H. Krause: Overexpression of calreticulin increases intracellular $\mathrm{Ca}^{2+}$-storage and decreases store-operated $\mathrm{Ca}^{2+}$ influx. J. Biol. Chem. 271: 9332-9339, 1996.

Mesaeli N., K. Nakamura, E. Zvaritch, P. Dickie, E. Dziak, K.H. Krause, M. Opas, D.H. MacLennan, M. Michalak: Calreticulin is essential for cardiac development. J. Cell Biol. 144: 857-868, 1999.

Michalak M., K. Burns, N. Mesaeli, C. Andrin, J.L. Busaan, G.H. Jass, M. Opas: Endoplasmic reticulum form of calreticulin modulates glucocorticoid-sensitive gene expression. J. Biol. Chem. 271: 29436-29445, 1996.

Michalak M., E.F. Corbett, N. Mesaeli, K. Nakamura, M. Opas: Calreticulin: one protein, one gene and many functions. Biochem. J. 344: 281-292, 1999.

Miller J.R., A.M. Hocking, J.D. Brown, R.T. Moon: Mechanism and function of signal transduction by the $\mathrm{Wnt} / \beta$-catenin and $\mathrm{Wnt} / \mathrm{Ca}^{2+}$ pathways. Oncogene 18: 7860-7872, 1999.

Nakamura K., A. Zuppini, S. Arnaudeau, J. Lynch, I. Ahsan, R. Krause, S. Papp, H. De Smedt, J.B. Parys, W. Muller-Esterl, D.P. Lew, K.H. Krause, N. Demaurex, M. Opas, M. Michalak: Functional specialization of calreticulin domains. J. Cell Biol. 154: 961972, 2001.

Ohashi T., D.P. Kiehart, H.P. Erickson: Dual labeling of the fibronectin matrix and actin cytoskeleton with green fluorescent protein variants. J. Cell Sci. 115: 1221-1229, 2002.

Opas M.: Adhesion of cells to protein carpets: do cells' feet have to be black? Cell Motil. Cytoskelet. 11: 178-181, 1988.

Opas M., M. Szewczenko-Pawlikowski, G.K. Jass, N. Mesaeli, M. Michalak: Calreticulin modulates cell adhesiveness via regulation of vinculin expression. J. Cell Biol. 135: 1913-1923, 1996.

Otey C.A.: pp $125^{\mathrm{FAK}}$ in the focal adhesion. Int. Rev. Cytol. 167: 161-183, 1996. 
Pahl H.L. and P.A. Baeuerle: Endoplasmic reticulum-induced signal transduction and gene expression. Trends Cell Biol. 7:50-55, 1997a.

Pahl H.L. and P.A. Baeuerle: The ER-overload response: Activation of NF-kappaB. Trends Biochem. Sci. 22: 63-67, 1997b.

Pankov R., E. Cukierman, B.Z. Katz, K. Matsumoto, D.C. Lin, S. Lin, C. Hahn, K.M. Yamada: Integrin dynamics and matrix assembly: tensin-dependent translocation of $\alpha_{5} \beta_{1}$ integrins promotes early fibronectin fibrillogenesis. J. Cell Biol. 148: 1075-1090, 2000.

Parsons J.T.: Integrin-mediated signalling: regulation by protein tyrosine kinases and small GTP-binding proteins. Curr. Opin. Cell Biol. 8: 146-152, 1996.

Peifer M. and P. Polakis: Cancer-Wnt signaling in oncogenesis and embryogenesis - a look outside the nucleus. Science 287: 1606-1609, 2000.

Piedra J., D. Martínez, J. Castaño, S. Miravet, M. Duñach, A.G. De Herreros: Regulation of $\beta$-catenin structure and activity by tyrosine phosphorylation. J. Biol. Chem. 276: 2043620443, 2001.

Rao A., C. Luo, P.G. Hogan: Transcription factors of the NFAT family: regulation and function. Annu. Rev. Immunol. 15: 707-747, 1997.

Rauch F., J. Prud'homme, A. Arabian, S. Dedhar, R. St Arnaud: Heart, brain, and body wall defects in mice lacking calreticulin. Exp. Cell Res. 256: 105-111, 2000.

Ridley A.J.: Rho GTPases and cell migration. J. Cell Sci. 114: 2713-2722, 2001.

Rohrschneider L., M. Rosok, K. Shriver: Mechanism of transformation by rous sarcoma virus: events within adhesion plaques. Cold Spring Harbor Symp. Quant. Biol. 46: 953-968, 1982.

Rojiani M.V., B.B. Finlay, V. Gray, S. Dedhar: In vitro interaction of a polypeptide homologous to human Ro/SS-A antigen (calreticulin) with a highly conserved amino acid sequence in the cytoplasmic domain of integrin $\alpha$ subunits. Biochemistry 30: 9859-9866, 1991.

Rottner K., A. Hall, J.V. Small: Interplay between Rac and Rho in the control of substrate contact dynamics. Curr. Biol. 9: 640-648, 1999.

Sadler I., A.W. Crawford, J.W. Michelsen, M.C. Beckerle: Zyxin and cCRP: two interactive LIM domain proteins associated with the cytoskeleton. J. Cell Biol. 119: 1573-1587, 1992.

Sastry S.K. and K. Burridge: Focal adhesions: a nexus for intracellular signaling and cytoskeletal dynamics. Exp. Cell Res. 261: 25-36, 2000.

Schaller M.D.: Biochemical signals and biological responses elicited by the focal adhesion kinase.
Biochim. Biophys. Acta Mol. Cell Res. 1540: 121, 2001.

Schwartz M.A., C. Lechene, D.E. Ingber: Insoluble fibronectin activates the $\mathrm{Na} / \mathrm{H}$ antiporter by clustering and immobilizing integrin $\alpha_{5} \beta_{1}$, independent of cell shape. Proc. Natl. Acad. Sci.USA 88: 7849-7853, 1991.

Schwartz M.A. and S.J. Shattil: Signaling networks linking integrins and Rho family GTPases. Trends Biochem. Sci. 25: 388-391, 2000.

Schwarzbauer J.E.: Fibronectin: from gene to protein. Curr. Opin. Cell Biol. 3: 786-791, 1991.

Sefton B.M. and T. Hunter: Vinculin: a cytoskeletal target of the transforming protein of Rous Sarcoma Virus. Cell 24: 165-174, 1981.

Seidensticker M.J. and J. Behrens: Biochemical interactions in the wnt pathway. Biochim. Biophys. Acta 1495: 168-182, 2000.

Senger D.R., A.T. Destree, R.O. Hynes: Complex regulation of fibronectin synthesis by cells in culture. Am. J. Physiol 245: C144-C150, 1983.

Shago M., G. Flock, C.Y.L. Hagesteijn et al.: Modulation of the retinoic acid and retinoid $\mathrm{X}$ receptor signaling pathways in P19 embryonal carcinoma cells by calreticulin. Exp. Cell Res. 230:50-60, 1997.

Shibasaki F., E.R. Price, D. Milan, F. McKeon: Role of kinases and the phosphatase calcineurin in the nuclear shuttling of transcription factor NF-AT4. Nature 382: 370-373, 1996.

Shriver K. and L. Rohrschneider: Organization of pp $60^{\text {src }}$ and selected cytoskeletal proteins within adhesion plaques and junctions of Rous Sarcoma Virus-transformed rat cells. J. Cell Biol. 89: 525-535, 1981.

Singer I.I.: The fibronexus: A transmembrane association of fibronectin- containing fibers and bundles of $5 \mathrm{~nm}$ microfilaments in hamster and human fibroblasts. Cell 16: 675-685, 1979.

Singer I.I.: Fibronexus formation is an early event during fibronectin- induced restoration of more normal morphology and substrate adhesion patterns in transformed hamster fibroblasts. J. Cell Sci. 56: 1-20, 1982.

St-Arnaud R., J. Prud'homme, C. Leung-Hagesteijn, S. Dedhar: Constitutive expression of calreticulin in osteoblasts inhibits mineralization. J. Cell Biol. 131: 1351-1359, 1995.

Turner C.E., J.R. Glenney Jr., K. Burridge: Paxillin: a new vinculin-binding protein present in focal adhesions. J. Cell Biol. 111: 1059-1068, 1990.

Turner C.E., F.M. Pavalko, K. Burridge: The role of phosphorylation and limited proteolytic cleavage of talin and vinculin in the disruption of focal adhesion integrity. J. Biol. Chem. 264:11938-11944, 1989. 
van der Heyden M.A., M.B. Rook, M.M. Hermans, G. Rijksen, J. Boonstra, L.H. Defize, O.H. Destree: Identification of connexin43 as a functional target for Wnt signalling. J. Cell Sci. 111: 1741-1749, 1998.

VerschuerenH.: Interference reflection microscopy in cell biology: methodology and applications. J. Cell Sci. 75: 279-301, 1985.

Volberg T., B. Geiger, R. Dror, Y. Zick: Modulation of intercellular adherens-type junctions and tyrosine phosphorylation of their components in RSV-transformed cultured chick lens cells. Cell Regul. 2: 105-120, 1991.

Volberg,T., Y. Zick, R. Dror, I. Sabanay, C. Gilon, A. Levitzki, B. Geiger: The effect of tyrosinespecific protein phosphorylation on the assembly of adherens-type junctions. EMBO J. 11: 17331742, 1992.

Wakasaki H., D. Koya, F.J. Schoen, M.R. Jirousek, D.K. Ways, B.D. Hoit, R.A. Walsh, G.L. King: Targeted overexpression of protein kinase $\mathrm{C}$ beta2 isoform in myocardium causes cardiomyopathy. Proc. Natl. Acad. Sci. USA 94: 9320-9325, 1997.

Wang Z., R. Tufts, R. Haleem, X. Cai: Genes regulated by androgen in the rat ventral prostate. Proc. Natl. Acad. Sci. USA 94: 12999-13004, 1997.

Wheeler D.G., J. Horsford, M. Michalak, J.H. White, G.N. Hendy: Calreticulin inhibits vitamin $\mathrm{D}_{3}$ signal transduction. Nucl. Acids Res. 23: 3268-3274, 1995.

Williams M.J., P.E. Hughes, T.E. O'Toole, M.H. Ginsberg: The inner world of cell adhesion: integrin cytoplasmic domains. Trends Cell Biol. 4: 109-112, 1994.
Woods A. and J.R. Couchman: Protein kinase C involvement in focal adhesion formation. J. Cell Sci. 101:277-290, 1992.

Xu W.M., H. Baribault, E.D. Adamson: Vinculin knockout results in heart and brain defects during embryonic development. Development 125: 327-337, 1998.

Yamada K.M. and S. Miyamoto: Integrin transmembrane signaling and cytoskeletal control. Curr. Opin. Cell Biol. 7: 681-689, 1995.

Yürüker B. and V. Niggli: $\alpha$-Actinin and vinculin in human neutrophils: Reorganization during adhesion and relation to the actin network. J. Cell Sci. 101: 403-414, 1992.

Zamir E. and B. Geiger: Molecular complexity and dynamics of cell-matrix adhesions. J. Cell Sci. 114: 3583-3590, 2001.

Zamir E., M. Katz, Y. Posen, N. Erez, K.M. Yamada, B.Z. Katz, S. Lin, D.C. Lin, A. Bershadsky, Z. Kam, B. Geiger: Dynamics and segregation of cell-matrix adhesions in cultured fibroblasts. Nat. Cell Biol. 2: 191-196, 2000.

Zapun A., N.J. Darby, D.C. Tessier, M. Michalak, J.J.M. Bergeron, D.Y. Thomas: Enahanced catalysis of ribonuclease $\mathrm{B}$ folding by the interaction of calnexin or calreticulin with ERp57. J. Biol. Chem. 273: 6009-6012, 1998.

Zhou Y., E. Dziak, M. Opas: Adhesiveness and proliferation of epithelial cells are differentially modulated by activation and inhibition of protein kinase $\mathrm{C}$ in substratum-dependent manner. J. Cell Physiol. 155: 14-26, 1993.

Address:

Michal Opas, Department of Laboratory Medicine and Pathobiology, University of Toronto, 1 King's College Circle, Medical Sciences Building, room 6326, Toronto, Ontario, M5S 1A8 Canada; m.opas@utoronto.ca 